\title{
The Impact of the COVID-19 Pandemic on the Use of Digital Technologies in Ensuring the Efficient e-Learning Process at the Technical University of Moldova
}

\author{
Dinu Țurcanu1,2, Rodica Siminiuc ${ }^{2,3^{*}}$, Viorel Bostan ${ }^{2,4}$ \\ ${ }^{1}$ Informatization, Partnerships, Institutional Image and Communication Office, Technical University of Moldova, Chisinau, \\ Republic of Moldova \\ ${ }^{2}$ Technical University of Moldova, Chisinau, Republic of Moldova \\ ${ }^{3}$ Doctorate and Postdoctoral Department, Technical University of Moldova, Chisinau, Republic of Moldova \\ ${ }^{4}$ Rector's Office, Technical University of Moldova, Chisinau, Republic of Moldova \\ Email: dinu.turcanu@adm.utm.md, ‘rodica.siminiuc@adm.utm.md, viorel.bostan@adm.utm.md
}

How to cite this paper: Țurcanu, D., Siminiuc, R., \& Bostan, V. (2020). The Impact of the COVID-19 Pandemic on the Use of Digital Technologies in Ensuring the Efficient e-Learning Process at the Technical University of Moldova. Creative Education, 11, 2116-2132.

https://doi.org/10.4236/ce.2020.1110154

Received: September 24, 2020

Accepted: October 24, 2020

Published: October 27, 2020

Copyright $\odot 2020$ by author(s) and Scientific Research Publishing Inc. This work is licensed under the Creative Commons Attribution International License (CC BY 4.0).

http://creativecommons.org/licenses/by/4.0/

\begin{abstract}
The Technical University of Moldova (TUM) is the only state-accredited technical higher education institution in the Republic of Moldova. In the face of the magnitude of the health crisis, TUM had to quickly adapt its mode of operation to ensure the continuity of its activities and to accompany its students in the study process in an efficient way. In this paper, we analyzed the impact of the COVID-19 pandemic on eLearning and on the use of Moodle and Microsoft 365 educational platforms, implemented at the Technical University of Moldova. The data were exported from M365 Usage Report in excel format for a period of 180 days (from 15.02 .2020 to 15.08 .2020 ) and from the Moodle database for a period of about 210 days (period 31.12.2019 - 31.07.2020). Those intervals include the pre-pandemic period, the lockdown period and the student holiday period. The aim of the research was to analyze the potential of the university to continue and ensure the online education process internally, to share the lived experience, the measures taken to anticipate the widening of the digital divide, but also for the identification of vulnerabilities and reasoned planning of exit strategies, in an appropriate frame of reference, depending on subsequent developments related to the COVID19 pandemic. The Technical University of Moldova anticipated and undertook multiple measures that demonstrated the potential to ensure the continuity and good development of the teaching process during the pandemic by: reducing the digital divide; reducing the risks of inequalities in education for students from disadvantaged backgrounds; ensuring the social binder (im-
\end{abstract}


perative during this period). At the same time, it would be incorrect not to mention that eLearning, although it is an indisputable support in the teaching process, requires additional investments (financial, time etc.) from the university and from the teachers, but also from the students!

\section{Keywords}

Information Technologies, Higher Education, Microsoft 365 for Education, Applications, Services, e-Learning, COVID-19, Technical University of Moldova

\section{Introduction}

The use of information and communication technologies (ICT) in higher education has been and is considered a necessary condition for adaptation to the European Higher Education Area (García-Valcárcel \& Tejedor, 2009). In recent years, there has been a dramatic increase in both the absorption of e-learning in higher education and research into its impact on institutions, teachers and students due to the possibility of expanding teaching and learning options using digital technologies (Rhona \& Benfield, 2005). The expansive and ever-fertile frontier of online learning has become the educational learning solution designed to improve knowledge and performance. Many educational institutions, corporate enterprises and other entities use web-based learning methodologies to provide education, in part or in full online, using electronic platforms. It is interesting to note that e-learning encapsulates web-based courses and all other asynchronous and synchronous learning methods, as well as other capabilities to support learning experiences (Kim, 2017). E-Learning is considered relatively new and, in terms of learning in general, is insufficiently researched. It has attracted and still attracts significant educational investment, but the educational value is often challenged (Rhona \& Benfield, 2005).

The COVID-19 pandemic caused a large number of casualties worldwide, with profound social and economic consequences. UNESCO noted that about one billion students have been forced to stay home due to the emergency, and the scale and speed with which schools and universities have been closed is an unprecedented challenge (Giancola \& Piromalli, 2020).

Since its inception, universities around the world, like any other social institution, have had to deal with devastating epidemics that have affected their daily functioning. And they survived, and continued their mission even behind closed doors, because academic activities continue where there are spirits engaged in science and training and sometimes with surprising results (UNESCO, 2020). It has certainly been redundant to observe the repercussions of the global pandemic on education and training systems around the world, forcing them to rely, in spite of everything, exclusively on digital technologies and distance learning to ensure their sustainability in the immediate future appropriate (Di Palma \& Belfiore, 2020). In order to face a daily life completely different from the one 
that characterized our days until recently, the institutions had to face digital transformations, being challenged to select resources and platforms that could be used to support online education. Institutions have experienced and still experience "digital immersion" with some drowning risks, inevitable to the situation "I throw you into the sea, so you will learn to swim". At the same time, it is pleonastic to say that this situation would have been much more difficult to face/sustain, if the internet had not been an important component of our lives. Some universities were already particularly focused on online teaching.

In these cases of pre-existence towards an orientation towards online didactics, the emergent period was probably faced with more decision, due to the presence of already institutionalized organizational practices (Giancola \& Piromalli, 2020). In many countries, various solutions have been implemented during the pandemic to continue the educational process. Online libraries, TV shows, guidelines, resources, video conferences, online channels have been introduced in at least 96 countries. During this difficult time, educational institutions were supported by large companies such as Microsoft, Google, Zoom and Slack, which offered many of the features of their products for free: Microsoft offered anyone the premium version of Microsoft Teams for free for six months and raised existing user limits. Google has announced that it is offering its corporate video conferencing features, for larger meetings (up to 250 people) and free G Suite and G Suite for Education registration functionality until July 1, 2020. Zoom has raised the time limit for video calls in China, Japan, Italy and the United States on demand (Mola, 2020).

\subsection{Objectives}

This study started as a necessity to evaluate the university potential in providing now, but also in the future, e-Learning, from the perspective of digital technologies implemented within the Technical University. The results will help us to take into account general variables involved in identifying organizational, procedural, infrastructural, pedagogical, social, but also administrative strategies for ensuring the university education process, regardless of the circumstances.

For the realization of this study the following objectives were proposed:

Assessing the impact of the pandemic on the use of Microsoft Office 365 services and applications and on the Moodle educational platform

Identifying the vulnerabilities, related to digital technologies, that the university has faced in order to ensure distance learning

Identifying possible solutions to solve or reduce the identified problems.

\subsection{Importance of the Study}

In the Republic of Moldova the pandemic is in a continuous linear evolution, registering an increase from 25113 cases (on 01.08.2020) to 37208 cases (on 01.09.2020) (Worldometer). The Extraordinary National Commission of Public

Health of the Republic of Moldova announced the extension until September 15, 
2020, on the entire territory of the country, the state of emergency in public health. The Ministry of Education, Culture and Research came up with the recommendation that universities, in the first 2 weeks, carry out their online study process. So, today we still have the present future in a computer always connected: lessons, teachers, exams, curriculum. The research focuses on the retrospective of the use of educational platforms implemented at the university and, respectively, the deduction of vulnerabilities in ensuring the educational process. At the same time, it emphasizes the importance of information technologies in the training process.

\section{Materials and Methods}

\subsection{Pandemic in the Republic of Moldova}

The state of emergency on the entire territory of the Republic of Moldova was declared on March 17, 2020, with a number of infected in a continuous linear evolution. On August 10, 2020, the Republic of Moldova registered 6802 cases per million population, the number of infections being higher than in Russia, but also compared to many European countries-Romania, Poland, Hungary, Czech Republic, Slovakia, Austria, Estonia, Latvia, Lithuania. In the face of the magnitude of the health crisis, Moldova was one of the 188 countries (Worldometer) worldwide that suspended the educational process. TUM, like many other educational institutions in the country, had to quickly adapt its mode of operation to ensure the continuity of its activities and to accompany its students in the study process in an efficient way. In the created situation, predictable or not, but the digital transformation, from opportunity and alternative has become, without much care, an imperative necessity.

\subsection{Research Approach}

This research includes an analysis of the university's potential for continuing and ensuring internally the online learning process, the availability of support and maintenance of IT services provided (Technical University of Moldova, 2020b). The impact of the Covid-19 pandemic on the services and applications of Microsoft 365 for Education implemented at the Technical University of Moldova was analyzed. The data was exported from the M365 Usage Report in excel format for a period of 180 days. The data was processed by secondary methods of quantitative research thanks to the wide range of data collection, but also the sincere and precise image, without discrepancies. The measurement number was taken as measurement criteria, as well as the volume of downloads/storage through the applications and services of educational platforms.

For a more efficient data screening, the 180 days were divided into weeks (25 26 weeks) (Technical University of Moldova, 2020b). For every 7 days the average value of the measurement criteria was calculated.

- The data analysis was performed, starting with 15.02 .2020 and ending with 15.08.2020. That interval was divided into 3 stages: 
- The first stage-15.02... 17.03.2020 - about 4 weeks until the closure of educational institutions in the Republic of Moldova due to the pandemic;

- The second stage-17.03... 15.06.2020 the period from the initiation of the state of emergency in the Republic of Moldova until the end of the summer session of the students;

- The third stage-15.06... 15.08.2020 the period after the end of the session and the beginning of the students' vacation.

- Also, the data taken from the university's Moodle Platform were taken over and analyzed (the data included the pre-pandemic period and the data from the pandemic period).

- For each diagram, a type trendline was identified for selecting the model used to determine the overall trend of the numerical series. The research design is presented in Table 1.

\section{Results}

This section may be divided by subheadings. It should provide a concise and precise description of the experimental results, their interpretation as well as the experimental conclusions that can be drawn. Currently, Microsoft Office 365 services benefit 19,052 from TUM members. Most users enjoy the services of Exchange (about 10,472 active users), Share Point and Teams (6730 and 6493 users, respectively). At the same time, very few users use Skype (175 active users) and practically, there is an extremely low use of Yammer services (48 users) (Figure 1, Figure 2).

\subsection{Evolution of the Number of Users and Activities by Service}

A comparative analysis of the evolution of Microsoft 365 services and applications involved in the teaching process in the pandemic period reports about a connection between them in the period up to the pandemic: the average values of the number of users varied around $550 \ldots 560$ people per day.

From the start of the emergency period until the end of the summer session (about 13 weeks) there was a linear increase in the number of Office users by

Table 1. The platforms and the period of their use in the given study.

\begin{tabular}{|c|c|c|c|}
\hline $\begin{array}{c}\text { Platforms implemented } \\
\text { within TUM }\end{array}$ & \multicolumn{3}{|c|}{ Report data } \\
\hline \multicolumn{4}{|l|}{ Microsoft Office 365 service' users } \\
\hline email activities & $15.02-17.03 .2020$ & $17.03-15.06 .2020$ & $15.06-15.08 .2020$ \\
\hline \multicolumn{4}{|l|}{ files stored in the cloud (One Drive) } \\
\hline users by platform & Week $1 \ldots 4$ & Week $5 \ldots 18$ & Week 19... 26 \\
\hline $\begin{array}{c}\text { Microsoft Office apps users } \\
\text { activities on M Teams }\end{array}$ & (until lockdown) & $\begin{array}{l}\text { (from lockdown to } \\
\text { summer session) }\end{array}$ & $\begin{array}{l}\text { (student holiday } \\
\text { period) }\end{array}$ \\
\hline \multicolumn{4}{|l|}{ users by type device (per MT) } \\
\hline Moodle & \multicolumn{3}{|c|}{ From 31 December 2019 to 31 July 2020} \\
\hline
\end{tabular}




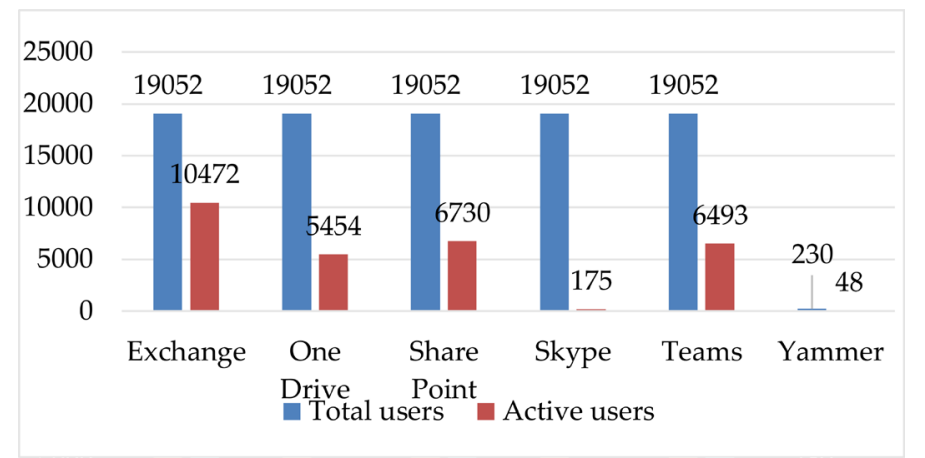

Figure 1. Microsoft Service users.

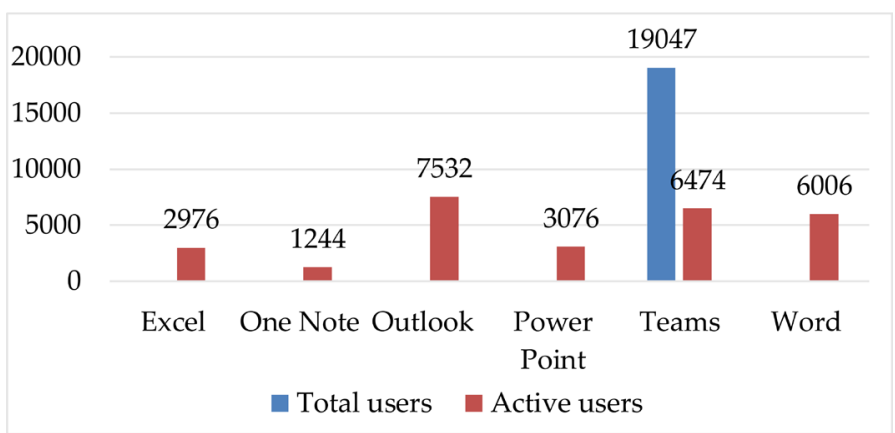

Figure 2. Microsoft Apps users.

553\% and an increase by $400 \%$ in Exchange services. Not very significant, however, the number of One Drive users increased linearly and a polynomial increase in Share Point users was also observed (Figure 3). With the end of the students' summer session, there is a gradual regression in the use of MOffice 365 services. There was a polynomial reduction in the number of users of Office, Exchange and Teams services, and the number of Share Point users decreased exponentially. The growing popularity of MOffice 365 applications is evident from the download data. It is relevant to mention that until the outbreak of the pandemic, the Teams application was used to a relatively small extent by the TUM community, the average number of users per day being about 50 people. The number of Teams users increased from 54 people to 2855 , which is $5187 \%$ (Figure 4).

However, the number of users is practically 2-3 times higher in that period, compared to the pre-pandemic period (Figure 5). And these results demonstrate, to a large extent, that the activity of teachers, management and the administrative body continued throughout the summer, in order to ensure, in the future, eLearning.

\subsubsection{Email Activities}

The number of actions for sending and receiving emails in the selected time period was $1.9 \mathrm{M}$, of which 517,117 emails sent, 1,375,434 emails received and 1 152,751 read. Even from the first week after the outbreak of the pandemic, the average number of emails sent per day increased sharply by $233 \%$, the maximum 


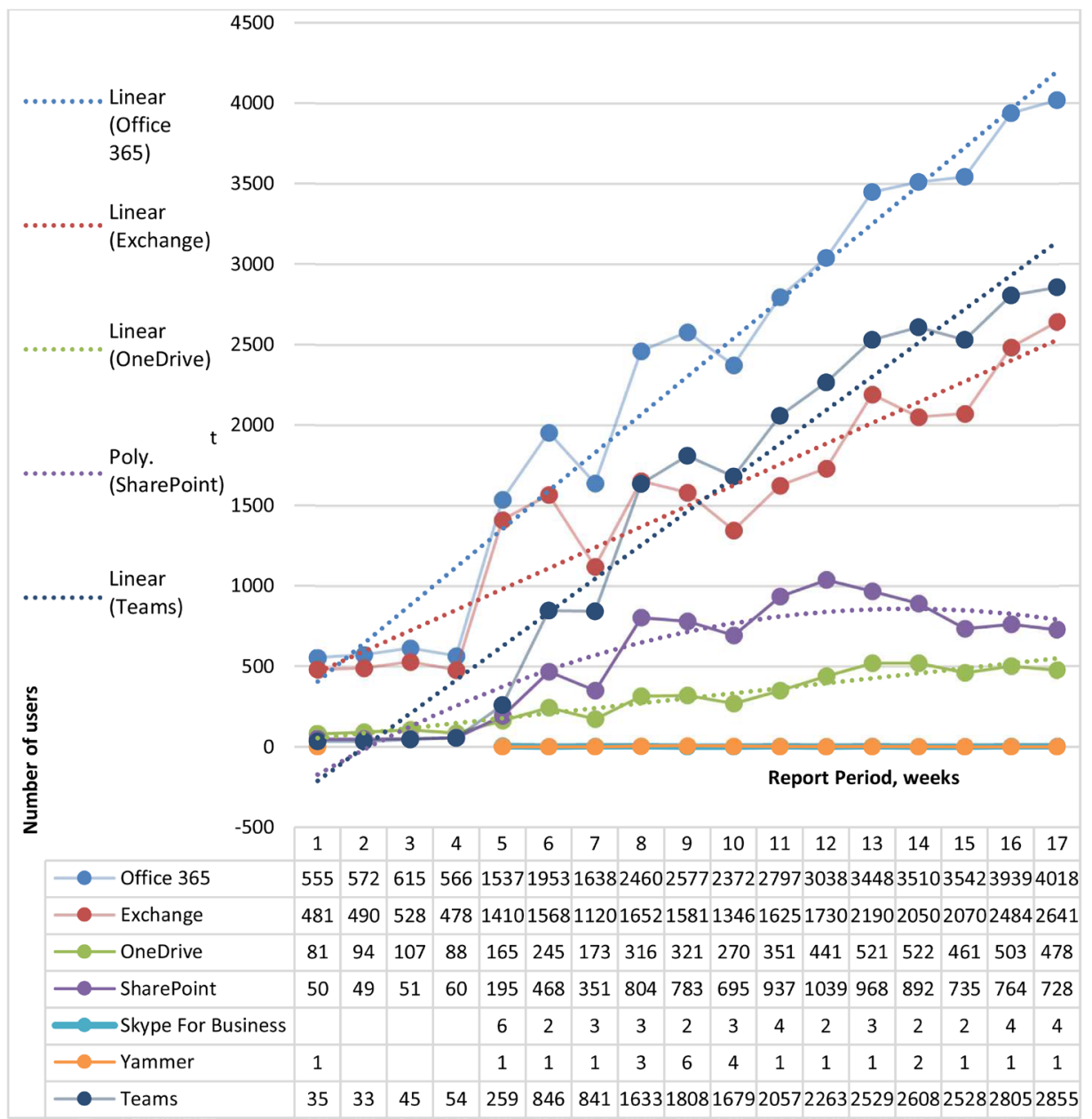

Figure 3. Number of Microsoft 365 service users (until the student session).

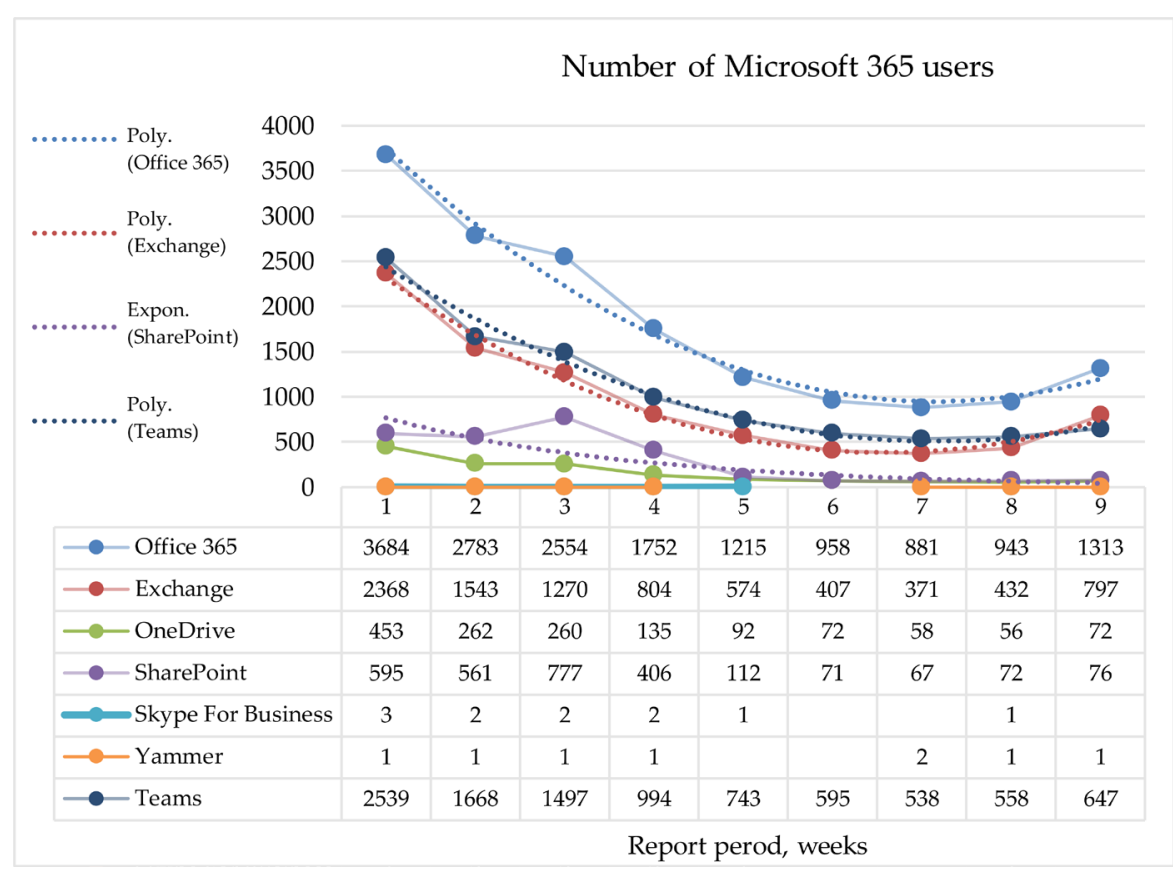

Figure 4. Number of Microsoft 365 service users (after student session). 


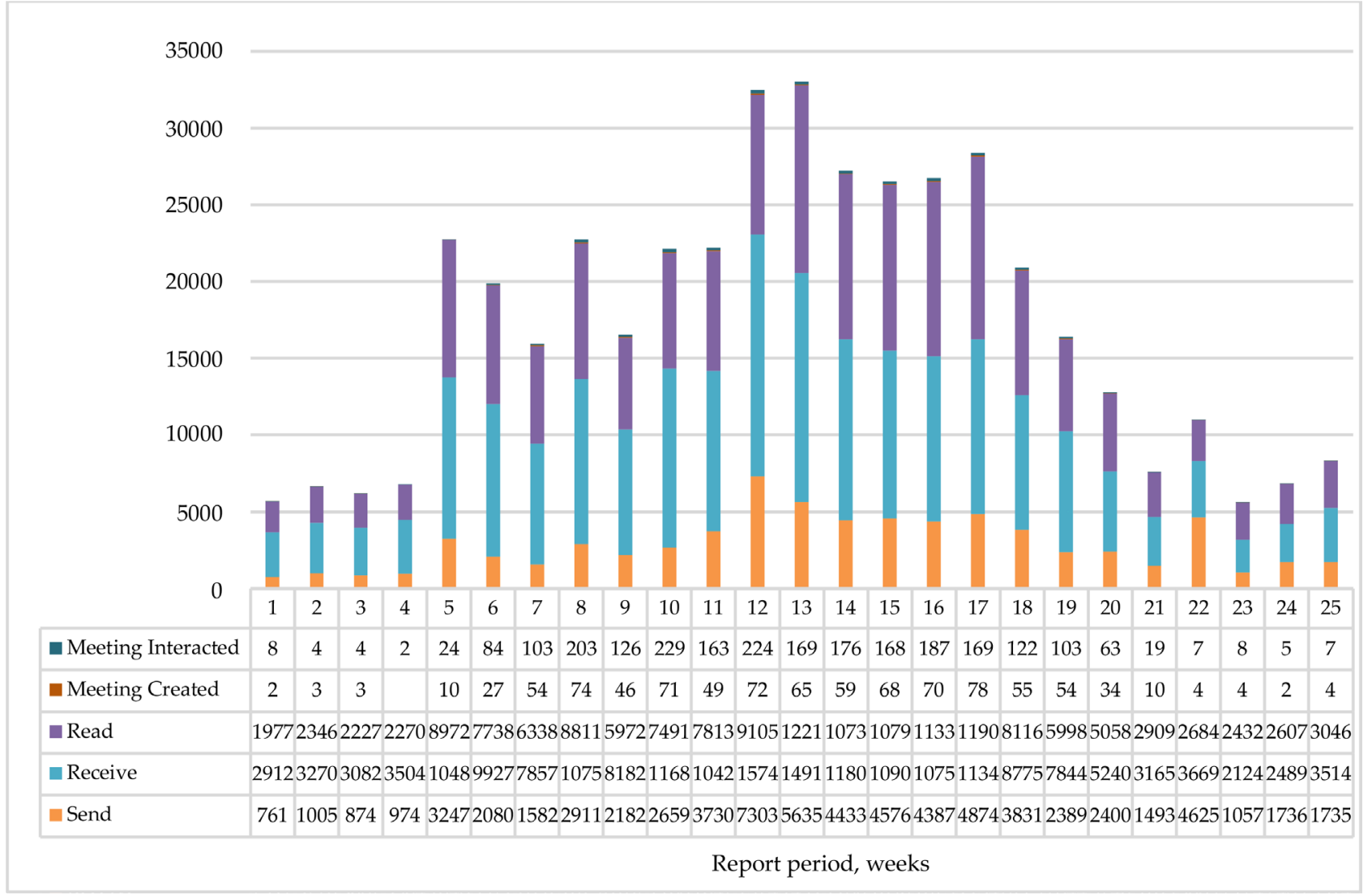

Figure 5. Email activities. Number of actions by type.

value being reached in the $12^{\text {th }}$ week (7303 emails per day), which is an increase of about $650 \%$ compared to the period until the pandemic. From the $18^{\text {th }}$ week there is a reduction in the number of activities which, however, exceeds the number of activities until the pandemic. If until the pandemic the number of meetings created was on average 2 - 3 per day, and the number of interactive meetings from 4 to 8 per day, then during the pandemic their number increased to $70-78$ meetings created and up to 230 interactive meetings, respectively (Figure 6).

\subsubsection{Email Activity Storage Usage}

It seems that the pandemic has only brought to the fore the acute need for cloud-based solutions. Microsoft OneDrive offers $15 \mathrm{~GB}$ of free storage + another 8 GB in bonuses, 1 TB via Office 365 account (Mihai \& Mihai, 2015). During the time reported in the paper, the academic community enjoyed more than ever the freedom to access, edit and share files on devices, regardless of location. The number of files stored in the cloud increased in a linear progression from $8.2 \mathrm{~TB}$ to $12.0 \mathrm{~TB}$ (Figure 7). The total number of files stored on the Cloud for 180 was 3.0 M. It is important to note that the majority of these stored files belong to video conferencing.

3.1.3. Microsoft 365 Apps Usage. Number of Daily Unique Users by Platform The total use of communication devices was calculated based on the total num- 
ber of connections of students, teachers and non-teachers (Figure 7).

Until the pandemic, the average number of users per day on the Web was about $385 \ldots 432$ people and $300 \ldots 337$ on Mobile. A sudden increase was observed from the $6^{\text {th }}$ week, and the maximum values were reached in weeks $14 \ldots$ 18 with values: web-2072 users per day (an increase compared to the period until the pandemic of about $418 \%$ ), mobile -2120 users per day (+597\%). The

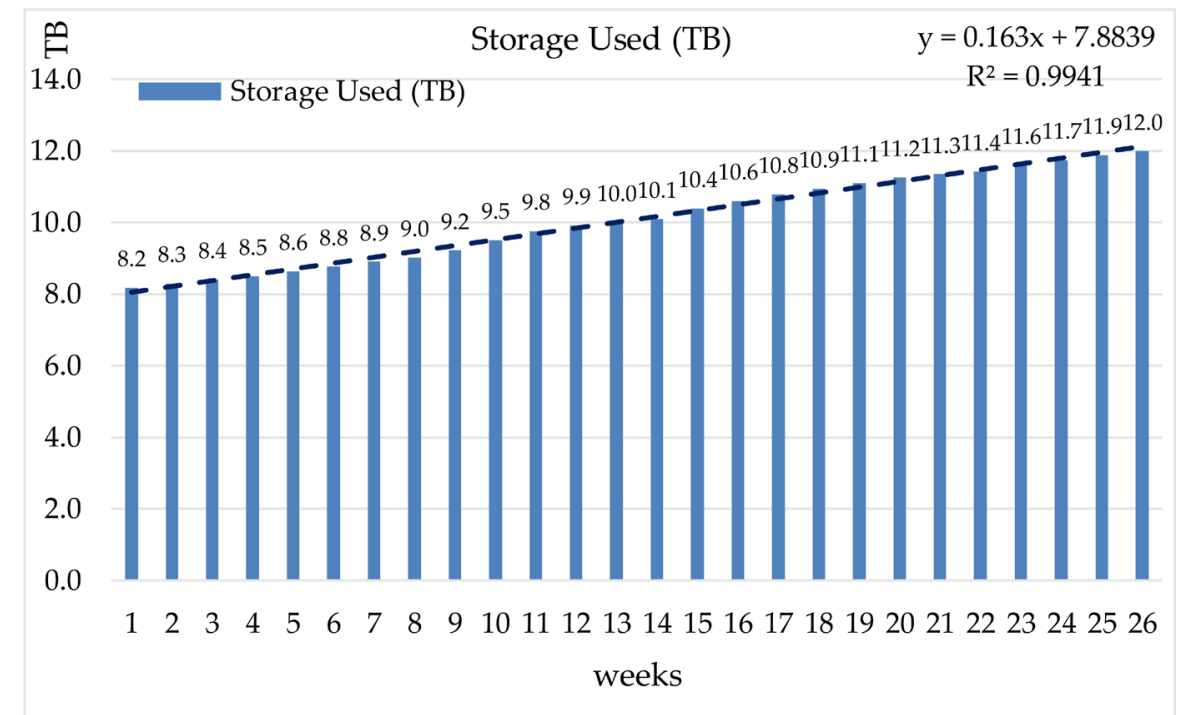

Figure 6. Storage used (OneDrive).

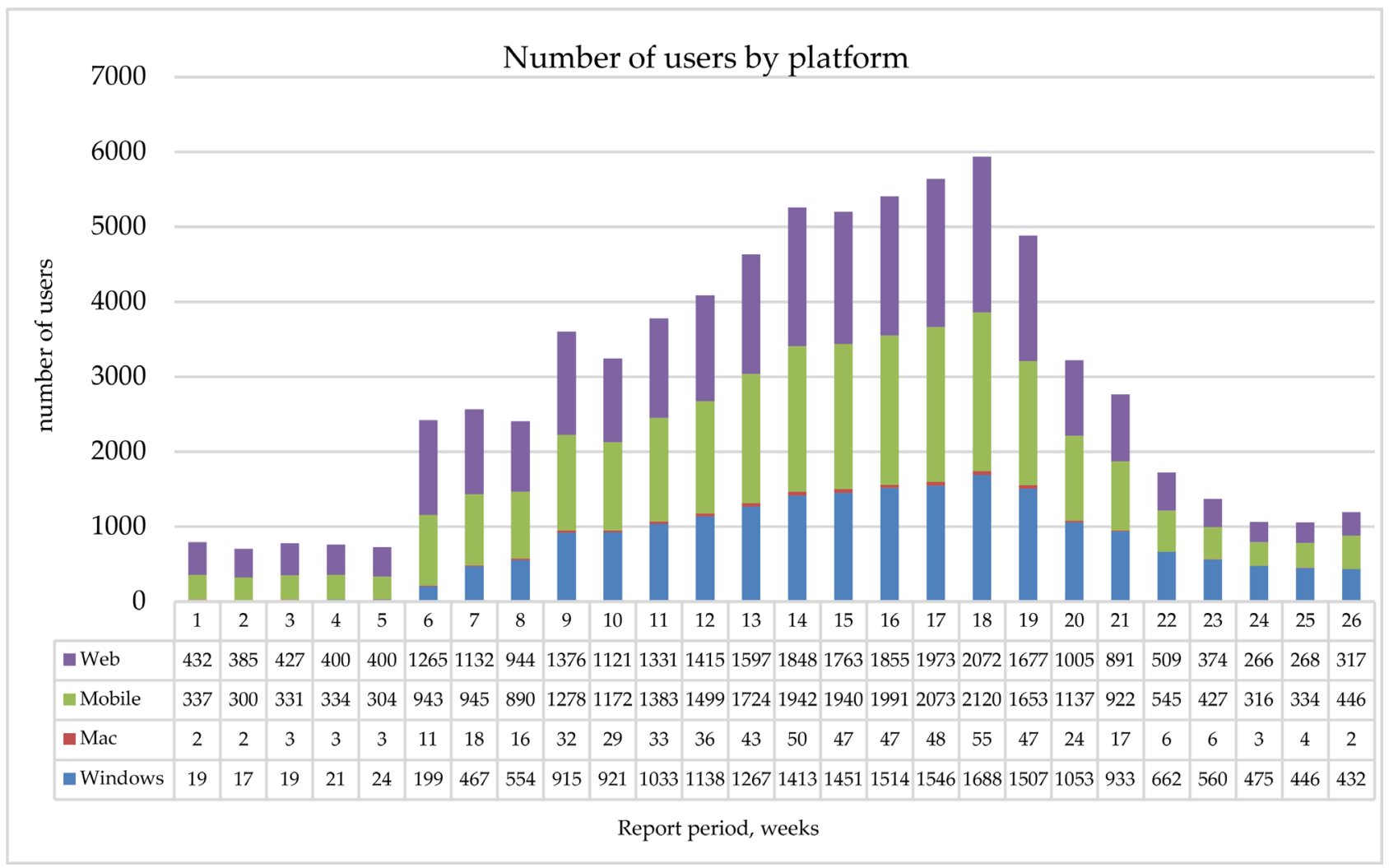

Figure 7. Number of users by platforms. 
number of users per day on Mac and windows increased to a maximum of 55 and 1688, respectively. As in the case of other analyzed services, after the end of the students' session the number of users on the platforms decreased, but it remained higher anyway compared to the daily average values up to the state of emergency.

\subsection{Evolution of the Number of Users by Application}

In the pre-pandemic period, Outlook and Word were the most used applications, averaging around 496... 538 users per day and 205... 262 users, respectively. Excel used an average of 70 users per day, and OneNote and Teams were used quite rarely, compared to the rest of the applications in the suite. The initiation of the lockdown contributed to a linear increase in the number of users of Outlook and Teams, and from the $9^{\text {th }}$ week the Teams application began to be used more than Outlook, reaching maximum values in the $17^{\text {th }}$ week: de 2864 users. The result is due to the increased number of sessions and video lessons organized on this application (Figure 8). With the end of the summer session of students there is a polynomial reduction in the number of users of Outlook, Excel, Word and Teams applications (Figure 9).

\subsubsection{User Activity of Microsoft Teams}

From the $4^{\text {th }}$ week of the research period, the use of Microsoft Teams became noticeable. In particular, the average number of connections per Private Chat

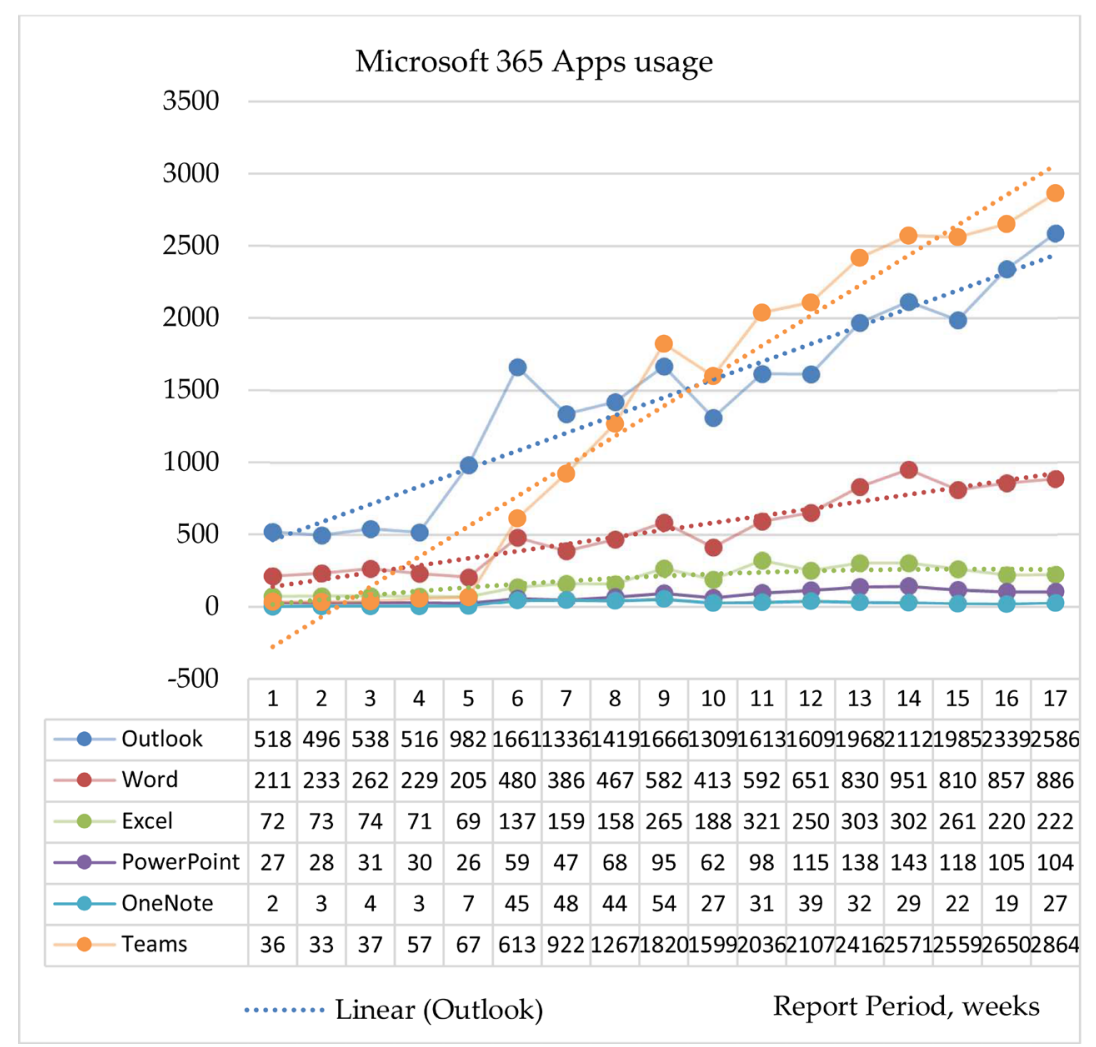

Figure 8. Number of Microsoft 365 Apps users (until the student session). 


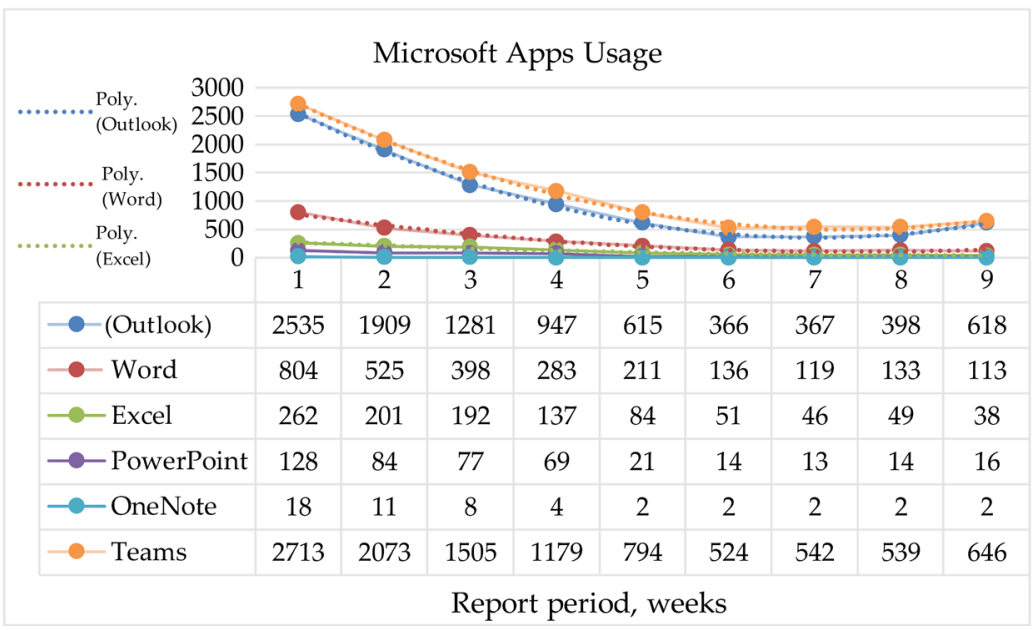

Figure 9. Number of Microsoft 365 Apps users (after student session).

Messages increased to 290 per day in the first week of the pandemic, and subsequently increased to a maximum of 4203 connections per day in the $12^{\text {th }}$ week, which is an increase of about $1350 \%$ compared to the first week of the pandemic. The situation is similar with Team Chat Messages connections: from 220 (on average per day) in the first week of the pandemic to an average of 1084 connections per day in the $11^{\text {th }}$ week. Although much of the eLearning activity up to the pandemic took place on the Moodle platform, an ascending number of meetings were recorded on Microsoft Teams. Even in the first week, the average number of video sessions per day organized was 29 , and on some days, it reached 234 meetings (Figure 10).

\subsubsection{Device Usage}

In a mobile and frantic period, we want quick and handy answers, using the closest device to make a decision, to learn something new or to get something. The accessibility of a fast connection and the opportunities offered by different devices connect people to devices more than ever. The image of how TUM users have used different devices for 180 days (from the pre-pandemic period to the present) shows that 1824 of them use Windows computers every day and 1991 Android operating systems. Only 380 of the users-web, 315-iOS and 45-Mac (Figure 11).

\subsection{Moodle Usage}

Prior to the pandemic, eLearning activities were supported, for the most part, on the Moodle platform, where there were already over $70 \%$ of the total number of courses. The statistical extraction of Moodle databases reports an increase in the total number of accesses, starting with February of this year: from 39,882 to 261,833 accesses in April, after which there is a slight reduction in the number of connections, in June they reached the value of 20,760. The number of user authentications reached a maximum of 12,234 at the end of March (Figure 12). 


\subsection{Graduate Questionnaire Results}

At the end of the study year, undergraduate students responded to a traditional survey, which included additional questions related to eLearning. Of the 1252 respondents, the majority, during their years of study, had the opportunity to access online courses on educational platforms, and the quality of use of educational tools considers it high and satisfactory. Regarding the usefulness of the implementation in the educational process of the online study modalities, 944 respondents consider it useful and very useful, and 185 people are undecided to appreciate it (Figure 13).

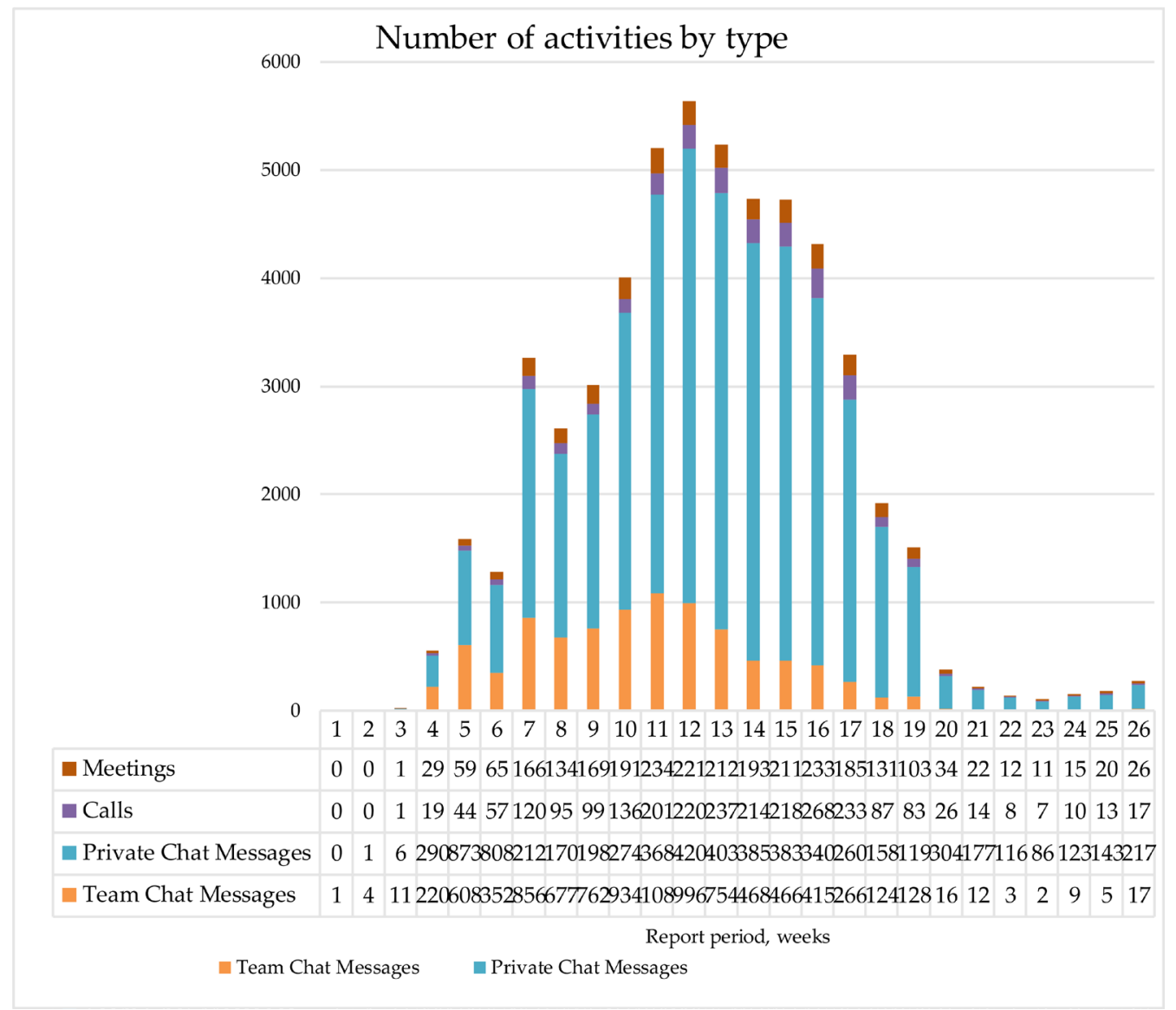

Figure 10. Number of activities by type (per MT).

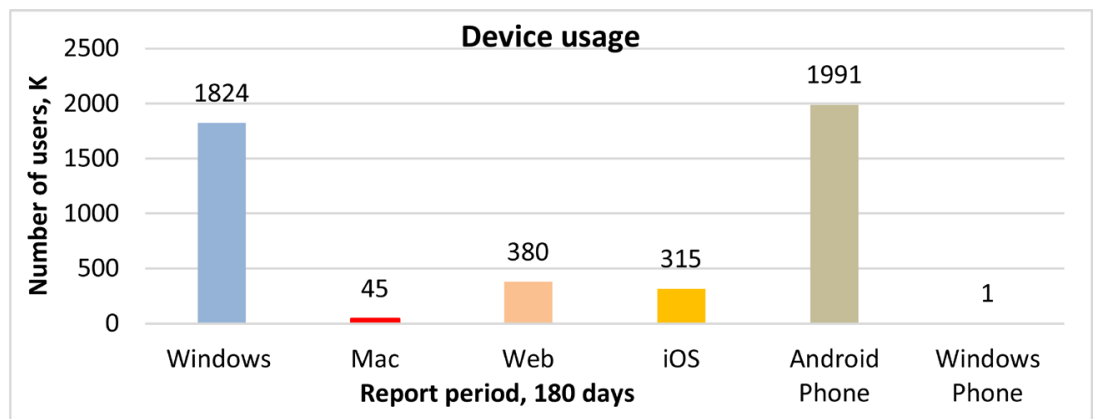

Figure 11. Number of users by device type over the selected time period. 


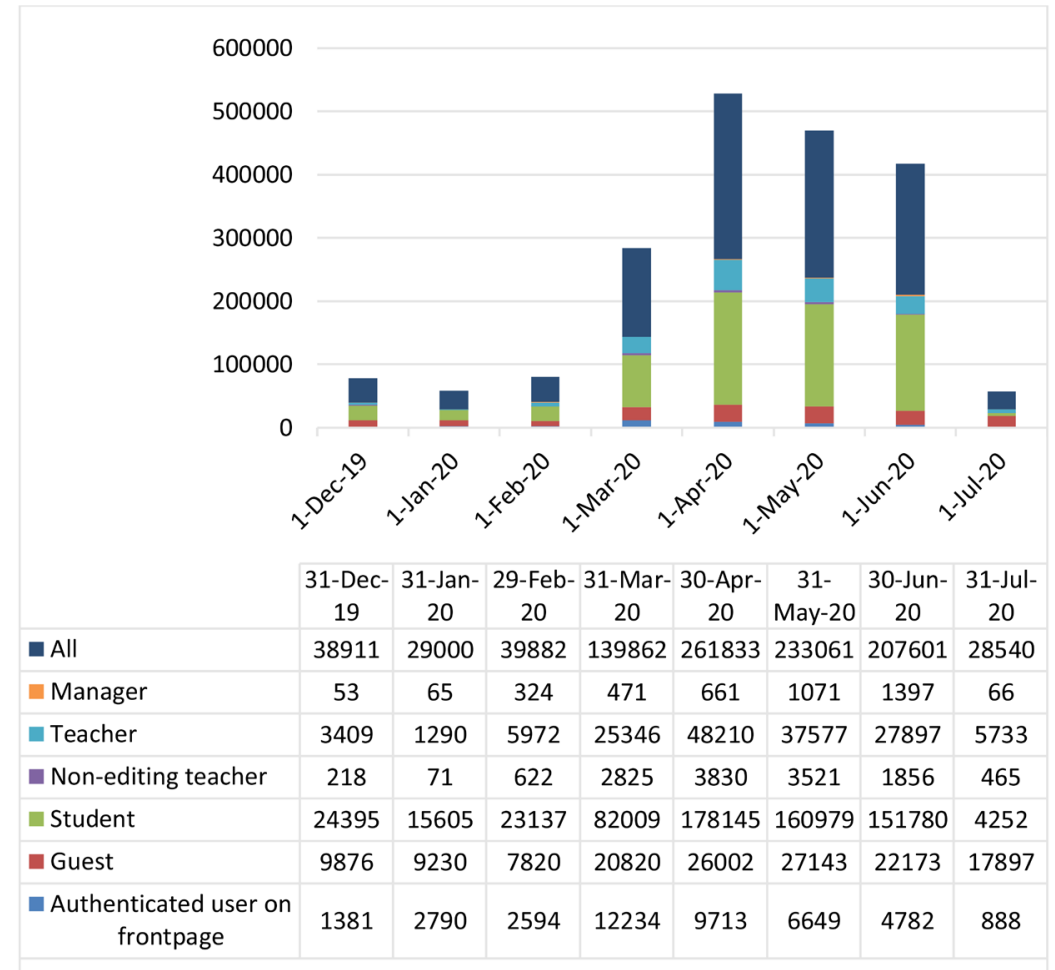

Figure 12. Number of accessions on the Moodle platform during december 31, 2019 until july $31,2020$.

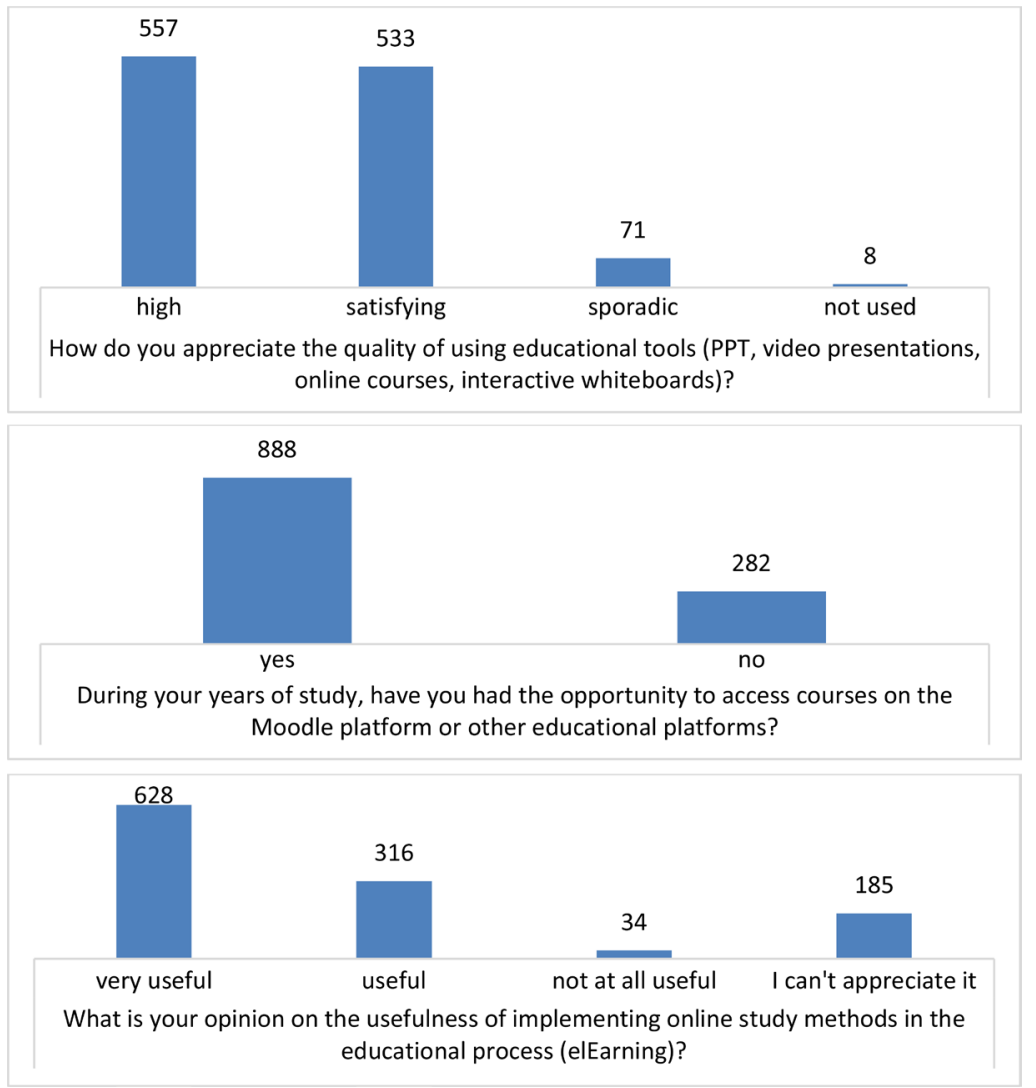

Figure 13. Questionnaire of 2020 graduates (1252 graduates, ISCED 6). 
Although the current impacts of the crisis on higher education are easy to document, it remains debatable which of them will leave their mark on the various actors in the medium and long term. The lack of references to similar crises in the past makes it difficult to predict what may happen in the immediate future (UNESCO, 2020).

\section{Discussion}

It is clear that the temporary global cessation of face-to-face activities has been a huge disruption to the functions of higher education institutions. The impact of these disruptions is highly variable. During the lockdown period, not without difficulties, but online teaching worked. Today we have the future in a computer always connected: lessons, teachers, exams, curricula. How it will affect the educational process in the future depends on the ability of educational institutions to remain active in its academic activities and on their financial sustainability.

In the context of the EU's call for additional information exchanges, good practices (UNESCO, 2020), we set out to share our experience on the impact of the pandemic on the use of the Microsoft Office 365 and Moodle educational platforms involved in the teaching process within TUM. We also share the measures taken to prevent the widening of the digital divide, but also to reduce the real risks of inequalities in education for students from disadvantaged backgrounds, etc.

At the same time, the research serves as a tool for identifying vulnerabilities and for reasoned planning of exit strategies, in an appropriate frame of reference, depending on subsequent developments related to the COVID-19 pandemic (European Council, Council of the European Union, 2020). What is certain is that, being "immersed in digital" during the lockdown period, we did not drown and we already have a semester of online studies behind us.

Among the problems that TUM encountered during the cessation of the traditional study process we could highlight:

\section{Lack of home computers for teachers.}

Tackling: Anticipating the pandemic, in order to stimulate and capitalize on the activity of teachers who excel in scientific, didactic and extra curriculum, 150 staff came into personal possession of laptops. This was the first stage of a longterm program, through which TUM aims to emphasize and stimulate the quality, professionalism, enthusiasm and involvement of teachers in the daily evolution of the academic community of TUM (Technical University of Moldova, 2020d). However, during the lockdown, when the need to be connected to a device was amplified, in order to ensure online teaching in the new year of study, stage II of digitization and additional IT tools was started at TUM, through a public tender and, as a result, another 200 laptops will be sent to teachers.

Lack of Internet services for the study process.

Tackling: based on the strategic partnership with the mobile operator in the country, in April 2020, 30 teachers, who lacked Internet services at home, were 
allocated 50 GB of free mobile Internet traffic per month until the end academic year 2019/2020, for online classes, which led to the realization of eLearning by these teachers.

Increased need for Internet traffic, call minutes etc.

Tackling: Based on the negotiations with one of the local mobile telephony operators, from April 1, 2020, voice subscriptions and reduced tariffs were offered to TUM corporate subscriptions. And all the packages used by UTM employees received significant improvements and reductions in price or Internet traffic included additionally, or quantity of minutes and SMS, and/or reduced price.

Lack of a unique network in student dormitories and study blocks.

Tackling: The Technical University of Moldova has 12 study blocks, which do not have a single wireless network, which makes it difficult to access the Internet in the university laboratories. Within a cross-border project (HARD) with "Gheorghe Asachi" Technical University of Iasi, Romania, the creation and modernization (where the network exists) of the unique corporate wireless network is expected, which would allow access based on the UTM corporate username to the public Internet network. Students who do not have the technical possibility (computer and/or Internet access) will be offered accommodation in the UTM dormitories where computer rooms will be created, to which they would connect to online training. Also, for some of the students, the possibility is discussed for them to use the TUM laboratories to connect to the online classes according to the schedule.

The epidemiological situation in the Republic of Moldova, at the moment, does not allow the beginning of the 2020/2021 study year in the traditional format. At the initiative of the Ministry of Education, Culture and Research, in the first two weeks, starting with September 1, will be organized online studies (TUM (2020)). And then, it will opt for a hybrid system (online lectures, and practical and laboratory activities, in groups small, with physical presence at university).

TUM, as a partner of the "Educatieonline" project (Technical University of Moldova, 2020a), ensures, through its technological classrooms, the filming of the curriculum for grades $1-12$ for the 2020-2021 study year. The project is a digital library, which contains, in the first stage, about 2500 video lessons for students in grades $1 \ldots 12$ and is expected in the second stage to reach about 4500 lessons. Benefiting from a unique experience in this project, TUM decided to create its own digital library with video lessons, lectures and practical activities for about 18 disciplines in various fields: mathematics, programming, physics, chemistry, technical drawing, mechanics. From 01.09. 2020, the library will become accessible and will contain over 1000 video teaching hours (Technical University of Moldova, 2020a). Thanks to this joint effort, especially valuable, in the new year of studies the Technical University of Moldova will provide video support for study subjects for first year students (Technical University of Mol- 
dova, 2020c).

In order to ensure the right to higher education for all, in a framework of equal opportunities and non-discrimination, as a first priority (UNESCO, 2020) the TUM administration is currently holding talks with representatives of the business environment dealing with the marketing of IT products. The shops are being asked to offer the possibility to TUM students to buy in installments computers or other IT equipment (tablets, notebooks, etc.), at a competitive price (for students) with $0 \%$ interest. Efforts to continue teaching courses in virtual mode have been notable and, given the lack of experience with similar situations in the past, the transfer has not been easy. Even in the best-case scenario, amplifying the measures to the desired level without the necessary technical support is impossible.

\section{Conclusion}

The Technical University of Moldova anticipated and undertook multiple measures that demonstrated the potential to ensure the continuity and good development of the teaching process during the pandemic by:

- reducing the digital divide;

- reducing the risks of inequalities in education for students from disadvantaged backgrounds;

- ensuring the social binder (imperative during this period).

At the same time, it would be incorrect not to mention that eLearning, although it is an indisputable support in the teaching process, requires additional investments (financial, time, etc.) from the university and from the teachers, but also from the students!

Of course, there are still many organizational, procedural, infrastructural, pedagogical, social, but also administrative and management issues that come into play. It is our duty, of the academic community, to analyze the possible future scenarios and to look, seriously and reflexively, for strategies that can be followed, regardless of the circumstances (Giancola \& Piromalli, 2020).

\section{Acknowledgements}

The research was funded by State Project 20.80009.5107.10 "Personalized nutrition and intelligent technologies for my well-being", running at Technical University of Moldova.

\section{Conflicts of Interest}

The authors declare no conflicts of interest regarding the publication of this paper.

\section{References}

Di Palma, D., \& Belfiore, P. (2020). Technology and Didactic Innovation in School at the Time of COVID-19: An Evaluation of the Educational Effectiveness in the Student 
Perspective.

European Council, Council of the European Union (2020). Countering the COVID-19 Crisis in Education and Training: Council Adopts Conclusions. European Council, Council of the European Union.

https://www.consilium.europa.eu/en/press/press-releases/2020/06/17/countering-the-c ovid-19-crisis-in-education-and-training-council-adopts-conclusions/

García-Valcárcel, A., \& Tejedor, V. L. (2009). Information and Communication Technologies in University Teaching: Implications in European Higher Education Space. International Journal of Human Sciences, 6, 683-696.

Giancola, O., \& Piromalli, L. (2020). Apprendimenti a distanza a più velocità. L'impatto del COVID-19 sul sistema educativo italiano. Il Mulino.

Kim, C. L. (2017). E-Learning, Information Technology, and Student Success in Higher Education. ORE.

Mihai, A., \& Mihai, L.-A. (2015) Online Storage-What Are the Best and Cheapest Services. GO4IT.

https://www.go4it.ro/content/internet/stocare-online-care-sunt-cele-mai-bune-si-mai-i eftine-servicii-9893361/

Mola, R. (2020). Microsoft, Google, and Zoom Are Trying to Keep up with Demand for Their Now Free Work-from-Home Software. Vox.

https://www.vox.com/recode/2020/3/11/21173449/microsoft-google-zoom-slack-increa sed-demand-free-work-from-home-software

Rhona, J. S., \& Benfield, G. (2005). The Student Experience of e-Learning in Higher Education: A Review of the Literature. Brookes eJournal of Learning and Teaching, 1, 1-9.

Technical University of Moldova (2020a). From September 1, 2020, UTM Will Operate an Ample Online Library. Chişinău: Technical University of Moldova.

https://utm.md/en/blog/2020/08/18/from-september-1-2020-utm-will-operate-an-amp le-online-library/

Technical University of Moldova (2020b). Microsoft 365 Admin Center. Chişinău: Technical University of Moldova.

https://admin.microsoft.com/Adminportal/Home?source=applauncher\#/homepage

Technical University of Moldova (2020c). UTM Is Preparing for Several Scenarios for the 2020/2021 Academic Year. Chişinău: Technical University of Moldova.

https://utm.md/en/blog/2020/08/05/utm-is-preparing-for-several-scenarios-for-the-20 20-2021-academic-year/

Technical University of Moldova (2020d). UTM Rector Rewards UTM Teachers with Laptops. Chişinău: Technical University of Moldova.

https://utm.md/en/blog/2020/01/27/utm-rector-rewards-the-utm-teachers-with-laptops/

TUM (2020). Announcement for First Year Students. Chişinău: Technical University of Moldova.

https://utm.md/en/blog/2020/08/25/announcement-for-first-year-students/

UNESCO (2020). COVID-19 and Higher Education: Today and Tomorrow. Impact Analysis, Policy Responses and Recommendations. International Institute for Higher Education in Latin America and the Caribbean.

Worldometer. https://www.worldometers.info/ https://www.worldometers.info/coronavirus/country/moldova/ 